Though there are many differences between health regions, there is some common ground. Most regional health authorities have appointed boards and are granted global budgets by their provincial governments. They also all lack control over two significant health care expenditures: physicians' fees and drugs. Another commonality, at least according to rural physicians, is that regional health authorities have not been kind to smaller communities.

For small communities, regionaliza- tion has, in effect, been centralization. In efforts to improve efficiency by reducing the duplication of services in areas of low population density, some regional boards have closed rural hospitals or have closed particular departments of regional hospitals. According to some doctors, the money saved might be coming at the cost of human lives. For instance, Ontario Ombudsman André Marin is investigating a regional health agency in the Niagara region after receiving numerous com- plaints that two emergency rooms in the area were closed without proper public consultation.

"It's not that we are against regionalization; it's just how it has been implemented in almost every region in Canada," says Dr. Karl Stobbe, president of the Society of Rural Physicians of Canada, who describes regionalization as "a euphemism for rural hospital closures." - Roger Collier, CMAJ

DOI:10.1503/cmaj.109-3166

\title{
Is regionalization working?
}

Previously published at www.cmaj.ca

$\mathrm{F}$ or more than a decade, the dominant model of health care in Canada has been regionalization, but health care experts still aren't sure if the national shift toward delivering medical services at the regional level has been successful. In the 1990s, when many provinces were implementing regional systems, advocates of regionalization were fond of tossing out grand-sounding promises: greater accountability, increased citizen participation in decision-making, better integration of services. Some of those promises were realized, experts say, while others turned out to be nothing more than unfulfilled optimism.

One phrase that comes up often in talks about regionalization is "from silos to systems." This refers to the shifting of service provision and decision-making power from local entities to larger, regional bodies which, the theory goes, can more effectively and efficiently deliver health care services. In the late 1990s, John Church, an associate professor in the School of Public Health at the University of Alberta in Edmonton, turned a critical eye toward regionalization in Canada and cast doubt on this theory.

"At a minimum, regionalization arrangements have to recognize that, given the varied nature of services, it is inadvisable to assume that cost savings and improved quality will flow from consolidation efforts," Church wrote in a 1998 paper (Int J Health Serv 1998;

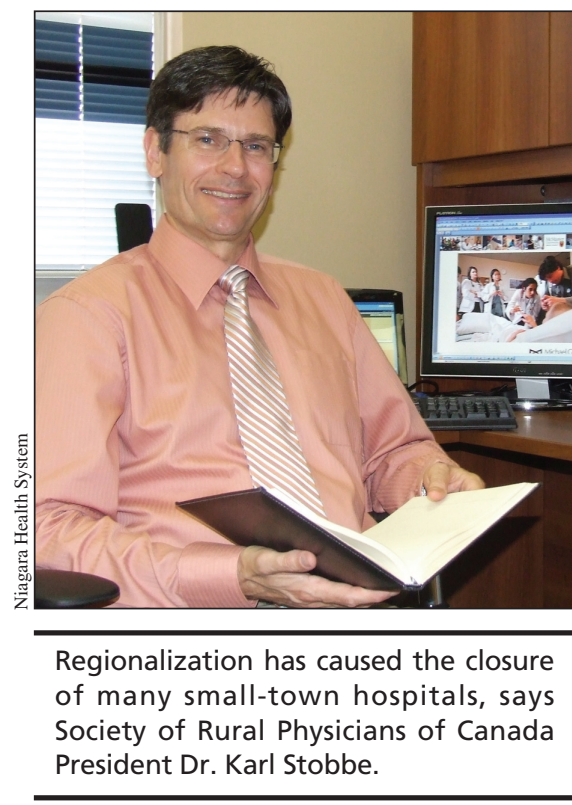

28:467-86). "All in all, regional populations in Canada might be too small to achieve any real economies of scale or to more generally effect a coordination of health services."

But as regional health authorities matured, Church says, they began to show more promise. For instance, regionalization has proven beneficial in areas where physicians need to keep busy to maintain important skills, such as surgical skills.

"Everybody who needed surgery would go to a smaller number of outlets and keep cardiovascular surgeons busy and not sitting around having their skills wax and wane," says Church.

One area where regionalization has failed, though, is in increasing citizen participation in health care decisionmaking. Engaging the public, of course, is not always easy. In his paper, Church cites the work of another researcher who looked at efforts to empower communities in the United Kingdom, Sweden and the United States but found: "In analysis of these three countries, one finding repeatedly emerged: no matter the organization arrangements or modes of financing, professionals dominated decisionmaking in the health sector." (Comp Politics 1985;17:399-420)

"Community participation is one part that never got off the ground, but governments weren't interested in that," says Church. "In fact, they were probably seriously interested in moving away from that model."

Another promise of regionalization was health care equity across provinces. Critics of regionalization, however, claim that the exact opposition may have happened - urban centres have gained more power while rural areas have lost power.

According to Dr. Karl Stobbe, president of the Society of Rural Physicians of Canada, regionalization has caused the closure of many smalltown hospitals. As a result, rural people - who "still get sick and injured whether there is a hospital or not" have lost their voice.

"Decision-making power almost always rests in urban centres," says Stobbe. "Our notion is that more than just the bottom lines of urban hospitals need to be looked at." 
Not everyone agrees that regionalization equals rural suffering. Many of the hospitals forced to close needed to close anyway, says Denise Kouri, who from 2002 to 2005 directed the nowdefunct Canadian Centre for Analysis of Regionalization and Health, which was based in Saskatoon, Saskatchewan.

"Under regionalization, a lot of those rural people are better served through regional services," says Kouri.

Though regionalization in Canada has not been properly evaluated, Kouri says, it would no doubt work better if provinces truly devolved power to the regions instead of treating them like "administrative bodies." She notes that health regions still don't have control over physicians' fees and drugs. Government refusal to relinquish power has, in fact, been a longstanding criticism of how regionalization has been implemented in Canada.

"Ultimately, however, the nature of a devolved authority, including the degree of power it can wield, is related less to its structural characteristics than to the outcome of the negotiation process that is an integral part of the devolution," researchers at McMaster University in Hamilton, Ontario, noted in 1997 (CMAJ 1997;156:371-7).

"An illustration of this fact is the provincial governments' unwillingness to relinquish financial control over two of the three biggest expenditure areas in health care - physicians' fees and drugs. These circumstances are less than optimal for devolved authorities that are intent on integrating and coordinating the primary care sector."

Overall, the jury is still out about regionalization. Experts note that there hasn't been enough evidence gathered to determine if regionalization is working in Canada, though that information may be coming soon.

"We are getting to a point where we can assess what might be the best system for a given population," says Pamela Fralick, president and chief executive officer of the Canadian Healthcare Association. "But often you have a lot of good intentions and best guesses." - Roger Collier, CMAJ

DOI:10.1503/cmaj.109-3167

\section{More news at www.cmaj.ca}

ClHR pledges to tackle primary health care: Canadian Institutes of Health Research officials say financial support will be bolstered for primary health care research. - Paul Christopher Webster, Toronto, Ont.

Physicians pressed to play nice: Canadian public health officials and provincial medical associations face criticism for failing to more widely implement collaborative approaches in the delivery of health care. - Paul Christopher Webster, Toronto, Ont.

Electronic health records: an asset or a whole lot of hype?: Strikingly different accounts of the importance of electronic health records in improving health outcomes for patients emerged at a national summit. - Paul Christopher Webster, Toronto, Ont.

Quebec delays construction of new hospitals: Proposals to build publicprivate partnership hospitals in Quebec must be resubmitted after exceeding original budget limits. - Laura Eggertson, Ottawa, Ont.

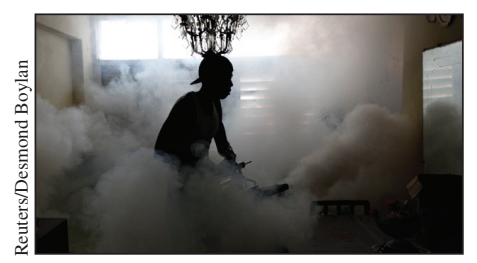

Dengue fever on the rise at tourist getaways: The incidence of dengue fever is rising as a consequence of such factors as increased international travel and, some say, global warming. Becky Rynor, Ottawa, Ont.

Medical education needs overhaul to train more user-friendly physicians, AFMC says: Physicians must be trained not just to deliver health care services but to be more socially responsible, accountable and willing to work as part of teams, says an Association of Faculties of Medicine of Canada report. — Roger Collier, CMAJ

Canada lags behind United States in drug return, reuse and recycling programs: While 38 of the United States have now accepted that drug recycling or redistribution programs are preferable to flushing drugs down the toilet to work their way into watersheds, various flora and fauna and eventually back into the human food chain, Canada has just two embryonic drug reuse programs. - Sabrina Doyle, Ottawa, Ont.

Lancet retracts 12-year-old article linking autism to MMR vaccines: Twelve years after publishing a landmark study that turned tens of thousands of parents around the world against the measles, mumps and rubella vaccine because of an implied link between vaccinations and autism, The Lancet has retracted the paper. - Laura Eggertson, Ottawa, Ont.

\section{Dispatches}

Crushed dignity: An Ottawa, Ontario, physician ponders the indignities of being a patient. - Jabir Jassam MD, Ottawa, Ont.

Olympic tears: A Granby, Quebec, physician discovers that carrying the Olympic torch can yield both laughter and tears. - Aline Levi MD, Granby, Que.

DOI:10.1503/cmaj.109-3176 cmaj.ca 